\title{
Effects of Rainfall on Vehicle Crashes in Six U.S. States
}

\author{
ALAN W. BLACK ${ }^{\mathrm{a}}$ AND GABRIELE VILLARINI \\ IIHR-Hydroscience and Engineering, The University of Iowa, Iowa City, Iowa \\ ThOMAS L. MOTE \\ Department of Geography, University of Georgia, Athens, Georgia
}

(Manuscript received 24 March 2016, in final form 1 August 2016)

\begin{abstract}
Rainfall is one of many types of weather hazard that can lead to motor vehicle crashes. To better understand the link between rainfall and crash rates, daily gridded precipitation data and automobile crash data are gathered for six U.S. states (Arkansas, Georgia, Illinois, Maryland, Minnesota, Ohio) for the period 19962010. A matched pair analysis is used to pair rainfall days with dry days to determine the relative risk of crash, injury, and fatality. Overall, there is a statistically significant increase in crash and injury rates during rainfall days of $10 \%$ and $8 \%$, respectively, leading to an additional 28000 crashes and 12000 injuries in the 1 May30 September period each year relative to what would be expected if those days were dry. The risk of crashes and injuries increases for increasing daily rainfall totals, with an overall increase in crashes and injuries of $51 \%$ and $38 \%$ during days with more than $50 \mathrm{~mm}$ ( 2 in.) of rainfall. While urban counties and rural counties with and without interstates each saw increased crash risk during rainfall, urban counties saw the most significant increases in relative risk. There are a number of exceptions to these broad spatial patterns, indicating that relative risk varies in ways that are not explained solely by meteorological factors.
\end{abstract}

\section{Introduction and background}

Motor vehicle crashes are an unfortunate by-product of an increasingly mobile world. While many crashes are primarily due to factors that the driver can control, such as impairment due to lack of sleep, consumption of alcohol, or other distractions (Andrey et al. 2013), numerous studies have demonstrated that inclement weather conditions can lead to increased risks of automobile crash, injury, and fatality. While a number of weather conditions such as frost, (Bergel-Hayat et al. 2013), temperature (Bergel-Hayat et al. 2013; Brijs et al. 2008), wind speed and direction (Brijs et al. 2008; Levine

\footnotetext{
${ }^{a}$ Current affiliation: Southern Climate Impacts Planning Program and Department of Geography and Anthropology, Louisiana State University, Baton Rouge, Louisiana.

O) Supplemental information related to this paper is available at the Journals Online website: http://dx.doi.org/10.1175/WCAS-D-16-0035.s1.

Corresponding author address: Alan W. Black, Department of Geography and Anthropology, Louisiana State University, Baton Rouge, LA 70803.

E-mail: ablack@1su.edu
}

et al. 1995), and visibility-reducing hazards such as fog, smoke, and dust (Ashley et al. 2015; Abdel-Aty et al. 2011) have been examined, most research has focused on crashes during rain and snow. Both frozen precipitation, such as snow, sleet, and freezing rain (Black and Mote 2015a,b; Andrey et al. 2013; Mills et al. 2011; Andrey 2010; Eisenberg and Warner 2005; Andreescu and Frost 1998), and rainfall (Jaroszweski and McNamara 2014; Andrey et al. 2013, 2003; Bergel-Hayat et al. 2013; Andrey 2010; Brijs et al. 2008; Keay and Simmonds 2005; Eisenberg 2004; Andreescu and Frost 1998; Levine et al. 1995; Andrey and Yagar 1993; Brodsky and Hakkert 1988; Bertness 1980; Sherretz and Farhar 1978) result in significantly elevated probabilities of crash as compared to dry days.

Meta-analysis of studies of weather-related crash risk in the United Kingdom, Canada, and the United States by Qiu and Nixon (2008) found that rainfall led to a $31 \%-111 \%$ increase in overall automobile crash rate, with injury crash rates increasing by anywhere from $28 \%$ to $70 \%$. A number of factors, both meteorological and nonmeteorological, contribute to the wide range of risk estimates found. Rainfall intensity (Hambly et al. 2013), 
daily rainfall accumulation (Eisenberg 2004), and time between rainfall events (Eisenberg 2004) have all been shown to influence crash risk. Nonmeteorological factors such as driver training and experience, light conditions, road design, speed limits, and changes in traffic volume during inclement weather (Black and Mote 2015b; Elvik 2006; Fridstrøm et al. 1995) can alternatively mitigate or contribute to crash risk depending on the specific circumstances.

Jaroszweski and McNamara (2014) suggest that the greatest influence on risk estimates may be the temporal and spatial scales used in the analysis. Temporal scales used in previous analysis have varied from monthly (Eisenberg 2004) to hourly (Andrey and Yagar 1993). The daily scale is often used, although it is acknowledged that a day with some rainfall may also contain many dry periods and that traffic volume varies considerably throughout the day (Jaroszweski and McNamara 2014; Hambly et al. 2013), leading to an underestimate of risk (Hambly et al. 2013; Brodsky and Hakkert 1988; Bertness 1980). Using a subdaily temporal unit can mitigate these issues; however, it is presumed that short-term adaptations in driver behavior also influence the risk of crash, and that these adaptations can exert a greater influence on the risk estimates when examined using a shorter temporal unit (Jaroszweski and McNamara 2014; Elvik 2006).

The spatial resolution of the analysis will also influence crash risk. Most studies use one meteorological station to represent the weather conditions for a city or county that may be several thousand square kilometers in size (Jaroszweski and McNamara 2014). Often, these stations are located at airports, which may be situated in outlying areas some distance away from the city being studied (Jaroszweski and McNamara 2014; Andrey et al. 2003). As a result, the precipitation values measured may not truly represent the meteorological conditions in a city center located far from the measurement location and/or be representative of rainfall across an entire area (Theofilatos and Yannis 2014). Jaroszweski and McNamara (2014) address this issue through the use of radar data with high spatial resolution $(5 \mathrm{~km})$ and suggest the use of radar or other types of gridded precipitation data to provide more representative measurements across study regions. Variation in crash risk between large and medium-sized cities in Canada (Andrey et al. 2013) and between urban and rural regions in the Netherlands (Bergel-Hayat et al. 2013) and in the Chicago area (Bertness 1980) suggests widespread differences in risk between urban and rural regions. The use of gridded data can allow risk to be assessed in rural areas or in any location where weather station data are unavailable.

Overall, while these investigations find that a number of factors can influence the magnitude of the risk estimate, they consistently demonstrate that rainfall leads to an increase in crash risk, due in part to factors such as reductions in both visibility and in friction between tires and the road. This analysis explores crash risk during rainfall for six U.S. states using daily gridded precipitation and county level crash data, expanding on previous research in a number of key ways. First, previous studies of crash, injury, or fatality during rainfall in the United States (e.g., Eisenberg 2004; Levine et al. 1995; Brodsky and Hakkert 1988; Bertness 1980; Sherretz and Farhar 1978) have typically focused on a single urban area (Levine et al. 1995; Bertness 1980; Sherretz and Farhar 1978) or on state-level measures (Eisenberg 2004; Brodsky and Hakkert 1988). Further, these examinations have used point measurements of rainfall from meteorological stations (Levine et al. 1995; Bertness 1980, Sherretz and Farhar 1978) or state-averaged rainfall (Eisenberg 2004; Brodsky and Hakkert 1988) in their analysis, which makes it difficult to capture localized variations in precipitation that would affect crash risk (Theofilatos and Yannis 2014). The combination of county-level crash data and gridded precipitation data in our study allows for a much finer spatial scale of analysis than previous works and is able to capture localized changes in precipitation that may be missed by point measurements. In addition, it allows for analysis of variation in risk between urban and rural locations, an area where additional research is needed (Theofilatos and Yannis 2014). Risk will also be examined by daily total rainfall as previous U.S. studies (Eisenberg 2004) found a positive relationship between risk and daily accumulation.

In summary, the research questions that we want to address are the following:

- What is the relative risk of crash, injury, and fatality in the six study states?

- What is the relationship between rainfall accumulation and relative risk?

- How do changes in exposure influence relative risk?

- Does relative risk of crash during rainfall differ between urban and rural areas?

Our results will provide a comprehensive assessment and quantification of the role played by rainfall in increasing car crashes, injuries, and fatalities over broad areas of the eastern and central United States.

\section{Data and methods}

\section{a. Data sources}

Analysis of crash risk due to rainfall requires two datasets: meteorological data and motor vehicle crash data. The source of rainfall data for this study was the 
Climate Prediction Center (CPC) Unified Gauge-Based Daily Precipitation (Higgins et al. 2000) database. The CPC dataset provides gridded precipitation values at $0.25^{\circ} \times 0.25^{\circ}$ resolution $^{1}$ across the continental United States. Values are calculated using observed precipitation measurements and interpolated to the grid using the optimal interpolation scheme with a correction for orographic bias (Xie et al. 2007). Daily accumulated precipitation values are for the period from $1200 \mathrm{Co}$ ordinated Universal Time (UTC) the day prior to the observation until 1200 UTC the day of the observation. As noted by Jaroszweski and McNamara (2014), the use of gridded data may result in improved risk estimates as the precipitation values may be more representative of actual rainfall over a large area; however, the daily temporal resolution is unable to capture variations in rainfall that are likely to be present within a single day.

Data on motor vehicle crashes were obtained from the National Highway Traffic Safety Administration's (NHTSA) State Data System (SDS). These data contain information on property damage only (PDO) crashes and the number of injuries and fatalities due to traffic collisions. SDS data are coded directly from police reports in the 32 states that participate in the system, although previous studies have noted the potential for underreporting of crashes during inclement weather (Brodsky and Hakkert 1988; Jaroszweski and McNamara 2014; Mills et al. 2011). There are also some temporal limitations associated with this dataset, as each state has a varying period of record and some states are missing data for one or more years. Despite these limitations, the SDS dataset is the only comprehensive dataset that contains information on automobile crashes, injuries, and fatalities, and serves as the source of crash data for this analysis.

\section{b. Methodology}

Gridded CPC rainfall and crash data for six states (Arkansas, Georgia, Illinois, Maryland, Minnesota, Ohio) from SDS were obtained for the years 1996-2010; however, there is some variability in the exact period of record used for each state based on the availability of the crash data (Table 1). Previous studies have shown that increases in crash relative risk (Black and Mote 2015b; Andrey et al. 2013; Mills et al. 2011; Andrey 2010;

\footnotetext{
${ }^{1}$ The size of each cell in kilometers varies due to the curvature of Earth; $0.25^{\circ} \times 0.25^{\circ}$ is approximately $27.8 \mathrm{~km} \times 18.7 \mathrm{~km}$ at $48^{\circ} \mathrm{N}$ in northern Minnesota at the northern part of the study area, and $27.7 \mathrm{~km} \times 24.1 \mathrm{~km}$ at $30^{\circ} \mathrm{N}$ in southern Georgia at the southern part of the study area.
}

TABLE 1. States used in this analysis and the corresponding period of record.

\begin{tabular}{llc}
\hline \hline \multirow{1}{*}{\multicolumn{1}{c}{ State }} & \multicolumn{2}{c}{ Period of record } \\
\cline { 2 - 3 } & Start & End \\
Arkansas & 1998 & 2010 \\
Georgia & 1996 & 2008 \\
Illinois & 1996 & 2010 \\
Maryland & 2000 & 2008 \\
Minnesota* & 1996 & 2010 \\
Ohio & 1996 & 2010 \\
\hline
\end{tabular}

* Minnesota data unavailable for 2003.

Eisenberg and Warner 2005; Andreescu and Frost 1998) and reductions in traffic volume (Qiu and Nixon 2008) are greater during winter precipitation than during rainfall, presumably due to differences in driver behavior and adaptation. As this work is focused on rainfall only, the analysis was restricted to the period from 1 May to 30 September for each year to greatly limit the influence of crashes involving winter precipitation. ${ }^{2}$ Rainfall amounts in the study states during the 1 May to 30 September period range from between $48 \mathrm{~cm}$ in northern Minnesota to around $60 \mathrm{~cm}$ in southern Georgia but can be highly variable as the precipitation is typically driven by convective processes (thunderstorms) that tend to vary in their spatial and temporal scales (e.g., Olson et al. 1995). While the CPC precipitation data are available at high spatial resolution (0.25 decimal degrees), the SDS data are aggregated to the county level. To address this scale mismatch, daily precipitation values were also aggregated to the county level based on the area weighted mean value of the CPC grid points within each county. Given the wide range in county sizes in the six study states, anywhere from 2 to as many as $40 \mathrm{CPC}$ grid points were used to calculate daily precipitation at the county level. Adjustments were also made to account for temporal differences between the datasets. While both datasets provided information on the date of the precipitation or crash, precipitation values for a given day are measured starting at 1200 UTC the day before and ending at 1200 UTC on the given day. In contrast, dates and times given in the crash data are based on the local time and date of the crash. The date and time for each crash were first converted from local time to UTC, and the date adjusted to match the

\footnotetext{
${ }^{2}$ Winter precipitation can occur in northern Minnesota after 1 May. This study considered over 186000 combinations of county and day in Minnesota, and winter weather was reported for approximately $0.23 \%$ of those county-day combinations. In a majority of cases, the snowfall measured was a trace (less than $2.54 \mathrm{~mm}$ or $0.1 \mathrm{in}$.).
} 
1200 UTC-1200 UTC definition of a day from the CPC precipitation data. After correcting for both spatial and temporal differences between crash and precipitation data, the result was a dataset containing precipitation values and the number of crashes, injuries, and fatalities for each day in the six study states, which was used in the subsequent analysis.

A matched pair design was adopted for the study, similar to many studies of precipitation-related crashes (Black and Mote 2015b; Jaroszweski and McNamara 2014; Andrey et al. 2003, 2013; Mills et al. 2011; Andrey 2010; Brodsky and Hakkert 1988). Each day with measurable precipitation in a county [ $\geq 0.254 \mathrm{~mm}(0.01 \mathrm{in}$.)] was paired with a control day in the same county where precipitation was absent. As in other studies (Black and Mote 2015b; Jaroszweski and McNamara 2014; Andrey et al. 2003, 2013; Mills et al. 2011; Andrey 2010; Brodsky and Hakkert 1988), matches were made such that control days were exactly one week before or one week after the precipitation day to control for factors such as daily traffic volume, light conditions, and other timesensitive factors, with the assumption that daily and day of week travel patterns are similar over time. Many of these studies (Andrey et al. 2013, 2003; Andrey 2010; Keay and Simmonds 2005; Levine et al. 1995; Andrey and Yagar 1993; Bertness 1980) note that traffic volume may be affected by holiday periods; however, major holidays during the 1 May-30 September period such as Memorial Day, the 4th of July, and Labor Day were not excluded from the analysis as they account for fewer than $2 \%$ of the study days. If a precipitation event was unable to be matched to a control, it was excluded from further analysis.

Once the numbers of crashes, injuries, and fatalities were tabulated for events and controls within a county, the relative risk of crash, injury, and fatality and the $95 \%$ confidence interval for each risk estimate were calculated using the odds ratio (e.g., Fleiss et al. 2003) approach, which has been used in several studies of crash risk due to precipitation (e.g., Black and Mote 2015b; Andrey et al. 2013; Hambly et al. 2013; Mills et al. 2011; Johansson et al. 2009). Odds are an expression of relative probability, represented as a ratio of the probability that an event will occur to the probability that the event will not happen (Fleiss et al. 2003). The odds ratio $\mathrm{OR}_{i}$ (or relative risk) represents the odds of a crash, injury, or fatality in a given county on an event day to the odds of a crash, injury, or fatality during a control day. This can be expressed using the following equation for any of the $i$ th matched pairs $(i=1 \ldots g)$ :

$$
\mathrm{OR}_{i}=\frac{\left(A_{i} / C\right)}{\left(B_{i} / D\right)}
$$

where $A_{i}$ is the number of collisions, injuries, or fatalities during a day with rainfall; $B_{i}$ is the number of collisions, injuries, or fatalities during the matched control day; and $C$ and $D$ are the number of safe outcomes during rainfall days and dry days, respectively. The values of $A_{i}$ and $B_{i}$ are contained in the traffic data, while $C$ and $D$ must be estimated. As there are thousands of vehicle trips and driving maneuvers in each study county every day that do not result in a crash, the values of $C$ and $D$ are very large and can be set in a somewhat subjective manner (Black and Mote 2015b; Mills et al. 2011). Two recent studies (Black and Mote 2015b; Mills et al. 2011) suggest a value of 1000000 for $C$ and $D$, and also conclude that the overall relative risk is not sensitive to the values chosen for $C$ and $D$ when both values are equal.

However, using the same fixed value for $C$ and $D$ introduces the assumption that traffic volumes are the same between events and controls. Most studies of crash risk do not adjust for exposure (e.g., Black and Mote 2015b; Jaroszweski and McNamara 2014; Andrey et al. 2013; Hambly et al. 2013; Mills et al. 2011; Andrey 2010; Eisenberg and Warner 2005; Andrey et al. 2003; Brodsky and Hakkert 1988; Fridstrøm et al. 1995) as this requires traffic volume data for the event and control that are difficult to obtain. However, rainfall does lead to a reduction in traffic volume (Cools et al. 2010; Qiu and Nixon 2008; Keay and Simmonds 2005; Eisenberg 2004). For example, vulnerable road users such as motorcyclists and pedestrians may choose not to travel or travel by other means during rainfall. When examining daily trends, Keay and Simmonds (2005) found that traffic volume decreased $0.08 \%$ for each $1.0 \mathrm{~mm}$ of rainfall. Therefore, the odds ratio in this study was calculated in two ways. The first was to assume that both $C$ and $D$ were equal with a value of 1000000 . The second was to use the daily precipitation value from the gridded CPC data and the traffic volume reduction of $0.08 \%$ $(1.0 \mathrm{~mm})^{-1}$ of rainfall from Keay and Simmonds (2005) to calculate an adjusted value of $C$ in Eq. (1). For example, a day with $10.0 \mathrm{~mm}$ of rain would result in the value of $C$ being reduced from 1000000 to 992000 . Each method has benefits and drawbacks. While the first method falsely assumes that there is no change in exposure during rainfall, Eisenberg (2004) notes that the effect of precipitation on crash rates is likely two orders of magnitude greater than the effect of the change in exposure during precipitation. Further, the first method produces results that are directly comparable with other studies that did not consider exposure. In contrast, the second method controls for exposure and results in a larger reduction in traffic volume on days when precipitation is heavier. However, the magnitude of the reduction is only informed by one study from Australia, 
which may not be applicable to the regions in this work. In the absence of traffic information for events and controls, both methods may provide reasonable estimates of the relative frequency of crash, injury, and fatality.

Once the odds ratio is calculated for an event-control pair, it is then log-transformed so that its distribution can be approximated by a normal distribution, and a weight inversely proportional to its variance based on the fixedeffects model for combining estimates risk is assigned (Black and Mote 2015b; Mills et al. 2011). The variance of the logarithm of the odds ratio is

$$
v_{i}=\frac{1}{A_{i}}+\frac{1}{B_{i}}+\frac{1}{C}+\frac{1}{D} .
$$

The statistical weight of each event-control pair is calculated:

$$
w_{i}=\frac{1}{v_{i}} .
$$

The weighted mean odds ratio and overall estimate of relative risk of crash based on a set of $g$ matched pairs, where $y_{i}$ is the logarithm of the odds ratio and "exp" is the exponential function is calculated:

$$
\bar{y}=\exp \left(\frac{\sum_{i=1}^{g} w_{i} y_{i}}{\sum_{i=1}^{g} w_{i}}\right) .
$$

Finally, the standard error of the risk estimate is used to calculate the $95 \%$ confidence interval for the weighted mean odds ratio (Johansson et al. 2009; Elvik et al. 2009):

$$
\begin{aligned}
& \text { 95\% Confidence Interval } \\
& =\exp \left[\left(\frac{\sum_{i=1}^{g} w_{i} y_{i}}{\sum_{i=1}^{g} w_{i}}\right) \pm \frac{1.96}{\sqrt{\sum_{i=1}^{g} w_{i}}}\right] .
\end{aligned}
$$

Values of relative risk greater than 1 indicate an increase in risk of vehicle crash, injury, or fatality during rainfall, while values less than 1 represent a decrease in risk. Relative risk was calculated for several different precipitation thresholds similar to those set by previous studies (Bertness 1980; Sherretz and Farhar 1978): all rain days $\geq 0.254 \mathrm{~mm}$ (0.01 in.), rain days $\geq 12.5 \mathrm{~mm}$ ( 0.5 in.), rain days $\geq 25 \mathrm{~mm}$ (1.0 in.), and rain days $\geq$ $50 \mathrm{~mm}$ ( $2.0 \mathrm{in}$.). The relative risk is useful for determining the overall change in risk that can be attributed to rainfall, and can also be used to examine the spatial variation in risk. It is important to note that the relative risk is not intended to and does not determine the absolute risk of collision (Andrey et al. 2003) or the risk to individual drivers (Andrey and Yagar 1993), and is likely to produce a conservative estimate of risk (Eisenberg 2004; Andrey et al. 2003; Andrey and Yagar 1993; Brodsky and Hakkert 1988; Bertness 1980).

To assess changes in relative risk between urban and rural areas, each county in the six study states was designated as urban or rural based on the "urbanized area" designation from the 2010 U.S. Census (U.S. Census Bureau 2015). Urbanized areas must meet minimum population density requirements and have a population of 50000 or more. Using ArcGIS software (ArcMap 10.3; http://desktop.arcgis.com/en/arcmap/), urbanized areas were overlaid on to a map of counties for each state, and those counties that intersected with urbanized areas were designated as "urban" for this analysis. The remaining rural counties were further divided into two categories based on the presence of an interstate highway. It is possible that the presence of a high-volume roadway in an otherwise rural county might change the relative risk during rainfall. Those counties that intersected with an interstate highway were labeled "rural interstate" and those that did not were classified as "rural." Of the 535 counties in the states analyzed, 171 were classified as urban, 114 as rural interstate, and 250 as rural (see supplemental Fig. S1).

Finally, the number of "excess" crashes and injuries was calculated, representing the number of additional crashes and injuries that occur on average each year due to rainfall during the 1 May-30 September period relative to what would be expected if those days were dry. While the relative risk based on the matched-pair analysis described above only considers rainfall days that can be matched with a dry control day, the excess crash method considers all rainfall days, including those that were not matched. For each county, the number of excess crashes per rainfall day was calculated by subtracting the average number of crashes or injuries per dry day from the average number of crashes or injuries per rainfall day. This was subsequently multiplied by the number of rainfall days during the study period for that county and divided by the number of years in the period of record to arrive at the annual average number of excess crashes per year due to rainfall in the 1 May-30 September period.

\section{Results and discussion}

This analysis initially focuses on the relative risk based on the CPC rainfall data, including an examination of the results by threshold and the effects of exposure. Subsequent sections explore the changes in risk between 
TABLE 2. Event/control pair and crash statistics.

\begin{tabular}{|c|c|c|c|c|c|c|c|c|}
\hline & & Arkansas & Georgia & Illinois & Maryland & Minnesota & Ohio & Overall \\
\hline \multicolumn{2}{|c|}{ Number of event/control pairs analyzed } & 45929 & 108413 & 78829 & 16117 & 63218 & 69473 & 381979 \\
\hline \multicolumn{2}{|c|}{ County with most matches } & 686 & 724 & 817 & 736 & 780 & 822 & 822 \\
\hline \multicolumn{2}{|l|}{ County with fewest matches } & 524 & 633 & 695 & 634 & 673 & 747 & 524 \\
\hline \multicolumn{2}{|l|}{ Average number of matches } & 612.4 & 681.8 & 772.8 & 671.5 & 726.6 & 789.5 & 709.1 \\
\hline \multirow{4}{*}{$\begin{array}{l}\text { Percentage of event/control } \\
\text { pairs with rainfall }\end{array}$} & $<12.5 \mathrm{~mm}$ & $78.9 \%$ & $82.6 \%$ & $80.6 \%$ & $81.9 \%$ & $84.8 \%$ & $83.2 \%$ & $82.2 \%$ \\
\hline & $\geq 12.5 \mathrm{~mm}$ & $21.1 \%$ & $17.4 \%$ & $19.4 \%$ & $18.1 \%$ & $15.2 \%$ & $16.8 \%$ & $17.8 \%$ \\
\hline & $\geq 25 \mathrm{~mm}$ & $7.8 \%$ & $5.5 \%$ & $6.5 \%$ & $6.2 \%$ & $4.8 \%$ & $4.8 \%$ & $5.8 \%$ \\
\hline & $\geq 50 \mathrm{~mm}$ & $1.6 \%$ & $1.1 \%$ & $1.0 \%$ & $1.3 \%$ & $0.8 \%$ & $0.5 \%$ & $1.0 \%$ \\
\hline \multirow[t]{3}{*}{ Totals for all rainfall events } & Crashes & 124136 & 623819 & 831312 & 202214 & 164229 & 781613 & 2727323 \\
\hline & Injuries & 87291 & 268252 & 264642 & 121998 & 82762 & 362956 & 1187901 \\
\hline & Fatalities & 1159 & 3105 & 2919 & 1214 & 1204 & 3011 & 12612 \\
\hline \multirow[t]{3}{*}{ Totals for all controls } & Crashes & 108275 & 539878 & 765075 & 174646 & 155402 & 707657 & 2450933 \\
\hline & Injuries & 78392 & 230830 & 250649 & 107472 & 81464 & 331397 & 1080204 \\
\hline & Fatalities & 1197 & 2956 & 3190 & 1263 & 1269 & 3353 & 13228 \\
\hline \multirow{3}{*}{$\begin{array}{l}\text { Average number of crashes } \\
\text { per rainfall event, by } \\
\text { severity }\end{array}$} & Crashes & 2.70 & 5.75 & 10.55 & 12.55 & 2.60 & 11.25 & 7.14 \\
\hline & Injuries & 1.90 & 2.47 & 3.36 & 7.57 & 1.31 & 5.22 & 3.11 \\
\hline & Fatalities & 0.03 & 0.03 & 0.04 & 0.08 & 0.02 & 0.04 & 0.03 \\
\hline \multirow{3}{*}{$\begin{array}{l}\text { Average number of crashes } \\
\text { during control periods, } \\
\text { by severity }\end{array}$} & Crashes & 2.36 & 4.98 & 9.71 & 10.84 & 2.46 & 10.19 & 6.42 \\
\hline & Injuries & 1.71 & 2.13 & 3.18 & 6.67 & 1.29 & 4.77 & 2.83 \\
\hline & Fatalities & 0.03 & 0.03 & 0.04 & 0.08 & 0.02 & 0.05 & 0.03 \\
\hline
\end{tabular}

urban and rural areas and the spatial distribution of relative risk.

\section{a. Relative risk based on CPC rainfall data}

For the six study states, a total of 381979 matched pairs were found, with more than 2.72 million crashes, 1.18 million injuries, and 12000 fatalities occurring on rainfall days, and more than 2.45 million crashes, 1.08 million injuries, and 13000 fatalities occurring on control days (Table 2). As would be expected, the daily average numbers of crashes, injuries, and fatalities are the highest in counties with higher population and in counties that contain major highways (Fig. 1). Matched pairs were not evenly distributed through the study states, partially due to the differing periods of record used in each state, or among the counties within each state. Georgia had the greatest number of matches, accounting for around $28 \%$ of the overall dataset, while Maryland had the fewest, representing just $4 \%$ of the overall data. Around $82 \%$ of the matched pairs were for daily rainfall less than $12.5 \mathrm{~mm}$, with just $1 \%$ of matched pairs for days with $50 \mathrm{~mm}$ or more. Overall, the proportion of the matched pairs at each precipitation threshold was similar across the six study states.

For the combined six-state data, significant increases were found in the relative risk of crash and injury during days with rainfall (Fig. 2, Table 3). The risk of crash for all six states combined is $10 \%$ higher during rainfall, while the risk of injury increases by almost $8 \%$. Our results show that rainfall leads to an additional 28000 crashes and 12000 injuries per year in the six study states during the May-September period in excess of what would be expected if those days were dry. Use of comprehensive unit costs from Blincoe et al. (2015) results in a conservative estimate of the economic losses attributable to these excess rainfall-related crashes of over 381 million U.S. dollars per year. ${ }^{3}$ Given that these results are only for a small number of states and months, it seems likely that rainfall leads to tens or perhaps hundreds of thousands of automobile crashes and injuries, and additional hundreds of millions of dollars in economic losses across the United States each year.

The risk of fatality during rainfall was not significantly different than during dry days, with a relative risk of 0.997. Previous studies (Andrey et al. 2003; Fridstrøm et al. 1995; Brodsky and Hakkert 1988) have found mixed results with regard to rainfall and fatal crashes and do not show a definitive link between rainfall and fatal crash rate (Qiu and Nixon 2008). However, the

\footnotetext{
${ }^{3}$ Based on the comprehensive unit cost for property damage only (PDO) crashes of $\$ 3862$ per crash and $\$ 21947$ per injury (based on the average value for MAIS0 and MAIS1 injury crashes) in 2010 dollars from Blincoe et al. (2015). MAIS is the maximum abbreviated injury scale and represents the maximum injury sustained.
} 

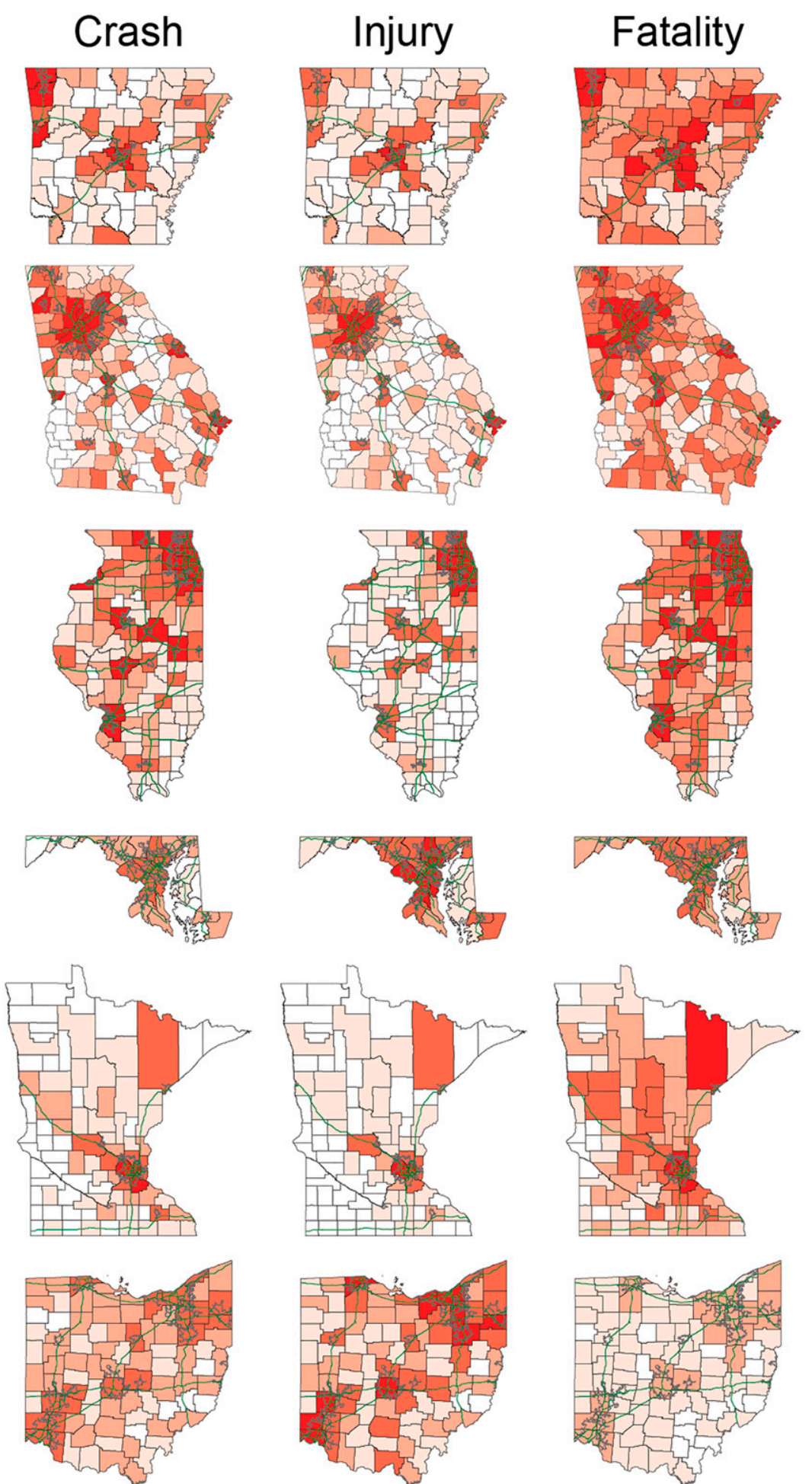

Daily Average Crashes and Injuries
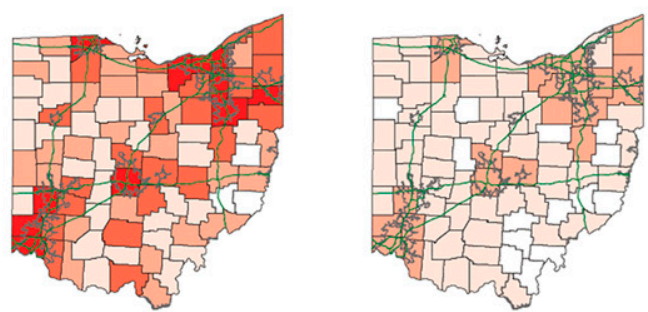

Daily Average Fatalities

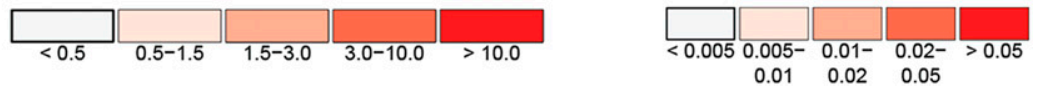

FIG. 1. Daily average number of crashes, injuries, and fatalities by county for each study state. Interstate highways appear in green, while urban areas are outlined in gray. 


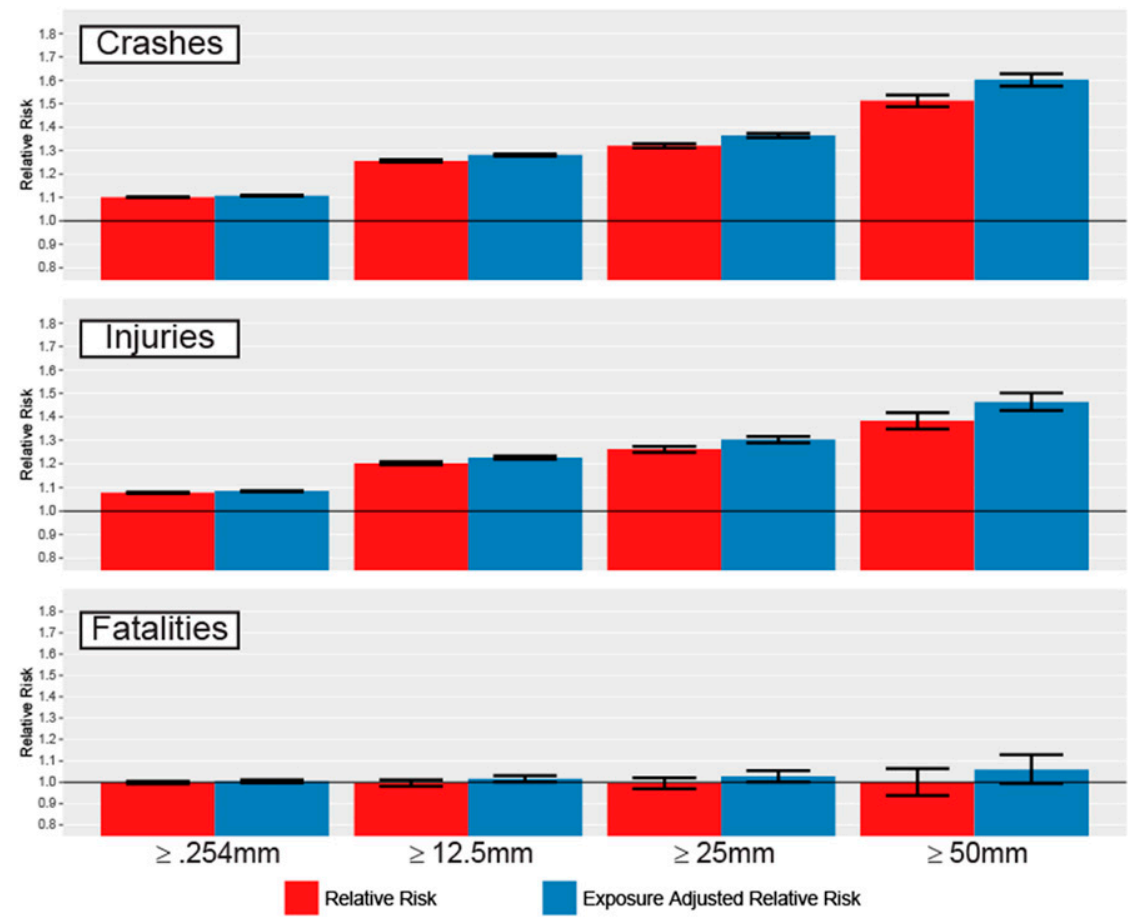

FIG. 2. Daily relative risk of crash, injury, and fatality during rainfall (red bar), during rainfall after adjusting for exposure (blue bar), and $95 \%$ confidence intervals for different daily precipitation accumulation thresholds.

results of Eisenberg (2004) show that daily rainfall totals have an important effect, as the fatal crash rate increases when daily rainfall is greater than $20 \mathrm{~mm}$, while lesser amounts of rainfall lead to decreases. In our study, only $5.8 \%$ of days had over $25 \mathrm{~mm}$ of rainfall, which may account for the lack of change in fatality risk. While the increases are not statistically significant even when adjusting for exposure, both Fig. 2 and Table 3 shows a positive relationship between daily precipitation totals and the relative risk of fatality, consistent with Eisenberg (2004).

While nearly every previous study has found that crash and injury risk increase during rainfall, there are

TABLE 3. Relative risk and $95 \%$ confidence interval for relative risk for the six study states combined by rainfall threshold and crash severity.

\begin{tabular}{|c|c|c|c|c|c|c|}
\hline & \multicolumn{3}{|c|}{ Relative risk } & \multicolumn{3}{|c|}{ Exposure-adjusted relative risk } \\
\hline & \multirow[b]{2}{*}{ Relative risk } & \multicolumn{2}{|c|}{$95 \% \mathrm{CI}$} & \multirow[b]{2}{*}{ Relative risk } & \multicolumn{2}{|c|}{$95 \% \mathrm{CI}$} \\
\hline & & Lower & $\overline{\text { Upper }}$ & & Lower & $\overline{\text { Upper }}$ \\
\hline \multicolumn{7}{|c|}{ All rainfall } \\
\hline Crash & 1.1006 & 1.0987 & 1.1024 & 1.1073 & 1.1054 & 1.1092 \\
\hline Injury & 1.0782 & 1.0754 & 1.0810 & 1.0847 & 1.0819 & 1.0875 \\
\hline Fatality & 0.9974 & 0.9912 & 1.0037 & 1.0033 & 0.9971 & 1.0096 \\
\hline \multicolumn{7}{|c|}{ Rainfall $\geq 12.5 \mathrm{~mm}$} \\
\hline Crash & 1.2557 & 1.2507 & 1.2607 & 1.2812 & 1.2761 & 1.2863 \\
\hline Injury & 1.2012 & 1.1939 & 1.2085 & 1.2255 & 1.2181 & 1.2330 \\
\hline Fatality & 0.9955 & 0.9809 & 1.0104 & 1.0156 & 1.0007 & 1.0307 \\
\hline \multicolumn{7}{|c|}{ Rainfall $\geq 25 \mathrm{~mm}$} \\
\hline Crash & 1.3212 & 1.3121 & 1.3303 & 1.3647 & 1.3553 & 1.3741 \\
\hline Injury & 1.2606 & 1.2473 & 1.2740 & 1.3020 & 1.2883 & 1.3159 \\
\hline Fatality & 0.9938 & 0.9683 & 1.0199 & 1.0263 & 1.0000 & 1.0533 \\
\hline \multicolumn{7}{|c|}{ Rainfall $\geq 50 \mathrm{~mm}$} \\
\hline Crash & 1.5127 & 1.4879 & 1.5380 & 1.6024 & 1.5761 & 1.6292 \\
\hline Injury & 1.3821 & 1.3471 & 1.4179 & 1.4638 & 1.4268 & 1.5018 \\
\hline Fatality & 0.9984 & 0.9369 & 1.0639 & 1.0584 & 0.9933 & 1.1279 \\
\hline
\end{tabular}


widely varying estimates of the magnitude of the increase. Both Jaroszweski and McNamara (2014) and Qiu and Nixon (2008) note that much of the variation in risk estimates among studies is due to methodological differences. The results of this study are most comparable to other studies that investigated risk at the daily temporal scale. These studies found that both the risk of crash and injury increased $10 \%-20 \%$ (Hambly et al. 2013; Keay and Simmonds 2005; Eisenberg 2004). Our results are consistent with these studies, although our estimates fall within the lower portion of the range for crashes and just outside the range for injuries. One possible reason for this may be that our study only examined crashes during the warm season months of MaySeptember. Many of the previous studies of relative risk considered rainfall crashes throughout the entire year. It is possible that differences in the character and scale (Olson et al. 1995) of warm season and cool season rainfall also have an effect on risk estimates that may partially account for the differences between studies. It is important to note that while there are some differences in risk estimates, our broad findings echo those of other studies: relative risk of crash and injury increases during rainfall.

As was found in previous studies (Andrey et al. 2003, 2013; Andrey 2010; Qiu and Nixon 2008; Hambly et al. 2013; Fridstrøm et al. 1995, Sherretz and Farhar 1978), increases in daily rainfall totals lead to increases in the risk of crash or injury (Fig. 2, Table 3). Overall crash risk increased by $26 \%$ on days with rainfall totals greater than or equal to $12.5 \mathrm{~mm}$ as compared to days without rainfall. Days with $25 \mathrm{~mm}$ of rainfall or more saw crash risk increase by $32 \%$ as compared to dry days, while those with $50 \mathrm{~mm}$ or greater had crash risk increases of $51 \%$. A similar pattern was found in injury crash risk, which saw increases of $20 \%, 26 \%$, and $38 \%$ over dry days when receiving daily rainfall $\geq 12.5 \mathrm{~mm}, \geq 25 \mathrm{~mm}$, and $\geq 50 \mathrm{~mm}$, respectively. Larger daily rainfall totals imply a combination of factors that could cause an increase in crashes, including greater duration of rainfall (more exposure), increased rainfall intensity (reduced visibility), and an increased potential for a loss of friction between tires and road surface. This is an important finding with respect to climate change. Increases in the frequency and/or intensity of rainfall under changing climate would be expected to result in more crashes (Hambly et al. 2013). Further, it is suggested by other studies that drivers do not become acclimatized to regional weather patterns over long periods (Andrey et al. 2013) and would be unlikely to adapt to more frequent or more intense rainfall; however, these factors that may lead to increased weather-related crash risk may be mitigated by future changes in other factors that influence crash risk. Given the considerable effect of daily rainfall totals on risk, they will be further explored in the subsequent section on the spatial characteristics of risk.

Most studies of crash risk acknowledge that traffic volume is reduced due to inclement weather, which can result in an underestimate of relative risk unless controlled for (Black and Mote 2015b; Jaroszweski and McNamara 2014; Andrey et al. 2003, 2013; Hambly et al. 2013; Mills et al. 2011; Andrey 2010; Eisenberg and Warner 2005; Brodsky and Hakkert 1988; Fridstrøm et al. 1995). As traffic volume data are difficult to obtain, most studies present a range of volume reductions and relative risk adjustments. In this study, we apply the traffic volume reduction of $0.08 \%(1 \mathrm{~mm})^{-1}$ of daily precipitation found by Keay and Simmonds (2005) to the relative risk calculation. For the six study states combined, the effect is to increase relative risk by about $1 \%$ for both crashes and injuries (Fig. 2, Table 3). However, the effect is much higher on days with greater rainfall. For example, on days with $\geq 50 \mathrm{~mm}$ of rainfall, the relative risk of crash increases from 1.51 to 1.60 when accounting for the reduction in traffic volume. As the effect on relative risk due to reduced exposure can be significant on days with large rainfall totals, it will also be addressed in subsequent sections.

\section{b. Urban/rural influences and spatial patterns of relative risk}

Several studies suggest that crash risk during rainfall varies between urban and rural regions (Andrey et al. 2013; Bergel-Hayat et al. 2013; Bertness 1980). Most previous studies of precipitation-related crash risk focused specifically on one city or metropolitan region, or were unable to examine the spatial patterns due to the sparse nature of meteorological station data. The use of gridded precipitation data allows us to explore the spatial patterns of relative risk, including changes in risk among urban and rural areas.

Overall, relative risk is significantly higher in urban counties as compared to rural interstate or rural counties (Fig. 3), consistent with the findings of Andrey et al. (2013). While there is a positive relationship between relative risk and rainfall totals in all county groups, risk increases much more rapidly for urban counties. For example, relative risk is about $5 \%$ higher in urban counties than in rural interstate or rural counties when examining all rainfall-related crashes, but is $20 \%$ higher than rural interstate and $30 \%$ greater than rural counties for days with at least $50 \mathrm{~mm}$ of rainfall. For injuries, the relative risk in urban areas is $5 \%$ higher than rural interstate or rural areas when considering all crashes, but increases to $16 \%$ and $29 \%$ respectively on days with at 


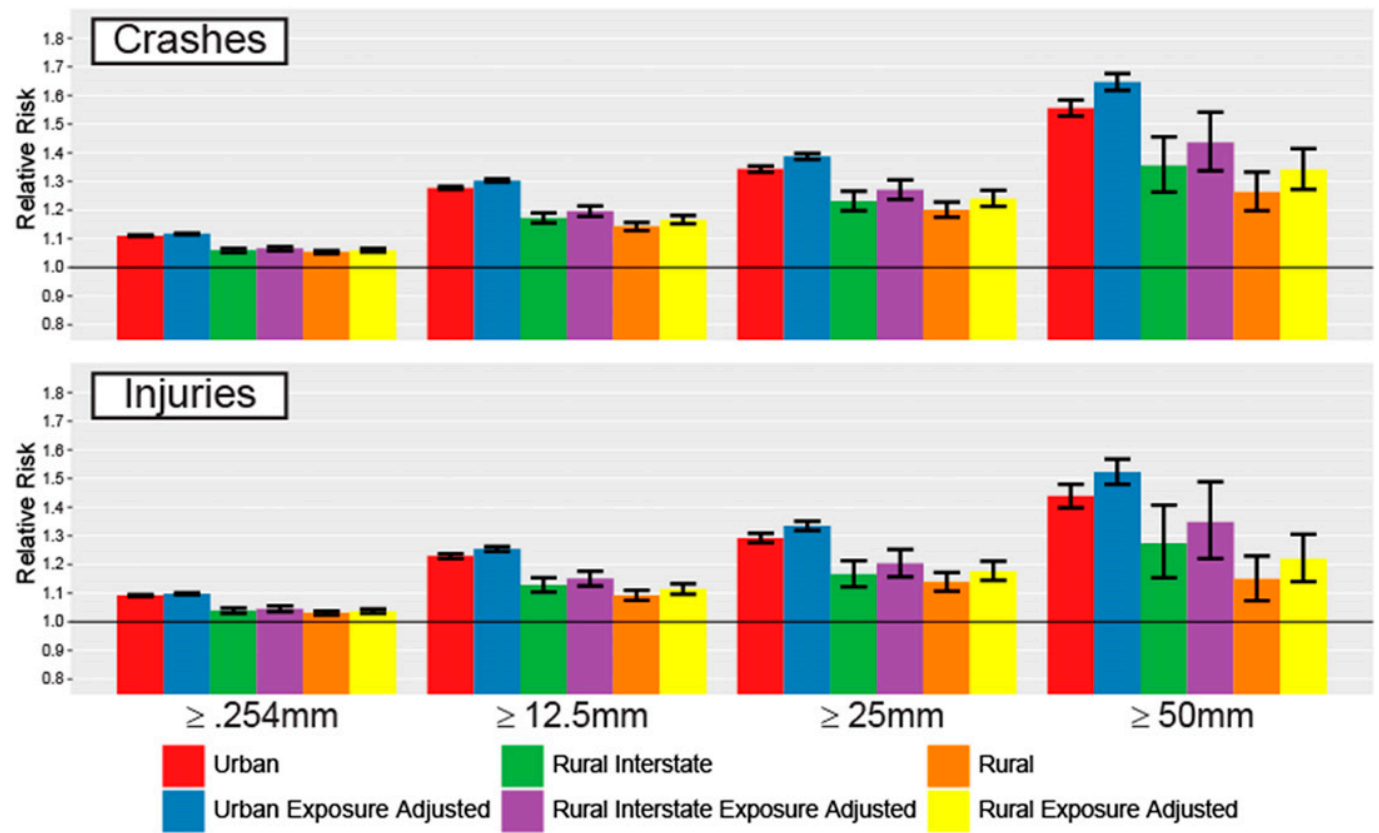

FIG. 3. Daily relative risk of crash, relative risk of injury, and $95 \%$ confidence intervals for urban counties (red bar), urban counties after adjustment for exposure (blue bar), rural interstate counties (green bar), rural interstate counties after adjustment for exposure (purple bar), rural counties (orange bar), and rural counties after adjustment for exposure (yellow bar) for different daily precipitation accumulation thresholds.

least $50 \mathrm{~mm}$ of rainfall. Similar patterns are found when accounting for the reduction in traffic volume caused by rain. Finally, the relative risk of fatality during rainfall does not differ significantly from the risk under dry conditions at any combination of region or daily rainfall threshold (Fig. S2).

There is considerable spatial variability in relative risk across the counties within the six study states (Figs. 4-9); however, caution must be used when interpreting these results as differences in regional and local climate affect the average exposure to rainfall on a rain day, with some locations averaging $1-2 \mathrm{~h}$ of rain per rainfall day and others as much 2 or 3 times that. As would be expected from the aggregate data, most counties see increased relative risk during rainfall. While some counties show decreases in relative risk for some combination of crash, injury, or rainfall total, only 5 out of a possible 4280 combinations result in a decrease that is statistically significant. There is considerable variability in relative risk estimates between counties and even within the same county at different rainfall thresholds. This does not appear to be driven by the number of days with rainfall exceeding a particular threshold. Elvik (2006) suggests that risk factors that are encountered less frequently by motorists will have a greater impact on crash rates and, conversely, factors that are encountered more frequently should have lesser impact. However, counties with fewer rainfall days at a particular threshold do not necessarily see higher relative risk.

Spatial variability in relative risk is generally minimized at lower daily rainfall totals, with most counties having increases in relative risk for both crashes and injuries. Variability is most evident at the higher precipitation thresholds, with more of a mix of high and low values. As would be expected from the results of the aggregated analysis, urban counties typically show increased relative risk at all thresholds, and in many cases the increases are significant. Urbanized counties and counties with major highways are likely to see more motorists impacted by rainfall than rural or sparsely traveled areas, lending confidence to the relative risk estimates (Jaroszweski and McNamara 2014). While the percentage increase in crash risk in many of these urban and/or heavily traveled counties is smaller than the increase in rural counties, the actual impact is much greater when considering the average number of crashes per day as shown in Fig. 1. Of the 100 most populous counties in the United States, 15 are within the six states examined in this research. These 15 counties account for $44 \%$ of the 28000 additional crashes and $42 \%$ of the 12000 injuries that occur during rainfall between May and September each year relative to what would be expected if those days were dry. 

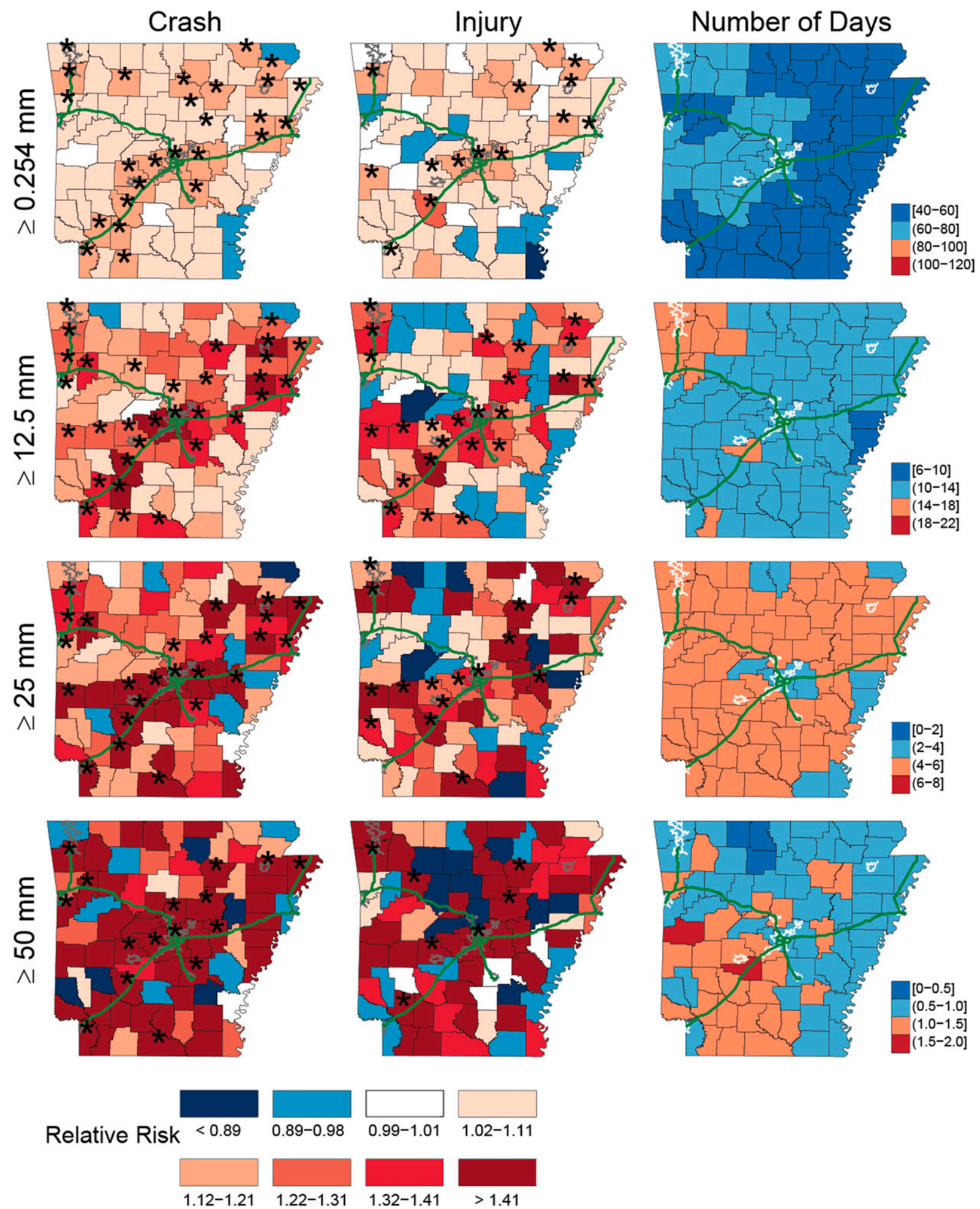

FIG. 4. Spatial distribution of relative risk of crash and injury on rainfall days for each precipitation threshold, and the average number of days meeting the threshold per year by county for the state of Arkansas. Counties that saw a significant increase (at the 95\% level) in relative risk are marked with a black asterisk, while counties with a significant decrease (at the $95 \%$ level) are marked with a black X. Interstate highways appear in green, and urban areas are outlined in gray for the relative risk maps and in white in the number of days maps. Counties with gray fill indicate that insufficient data were available to estimate relative risk. 

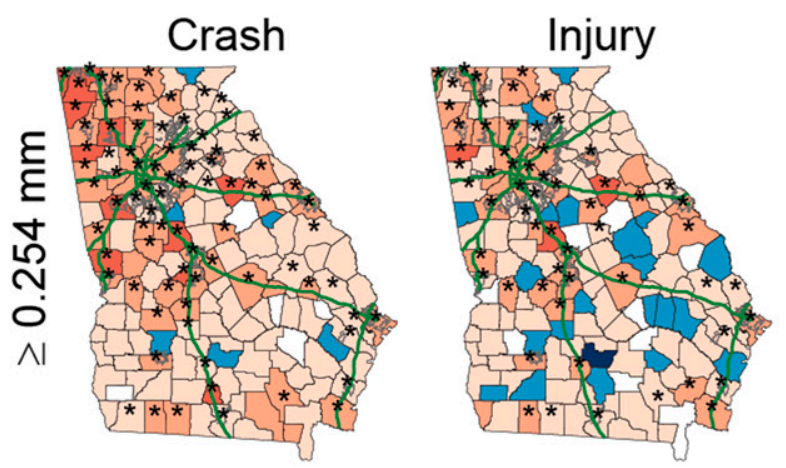

\section{Number of Days}
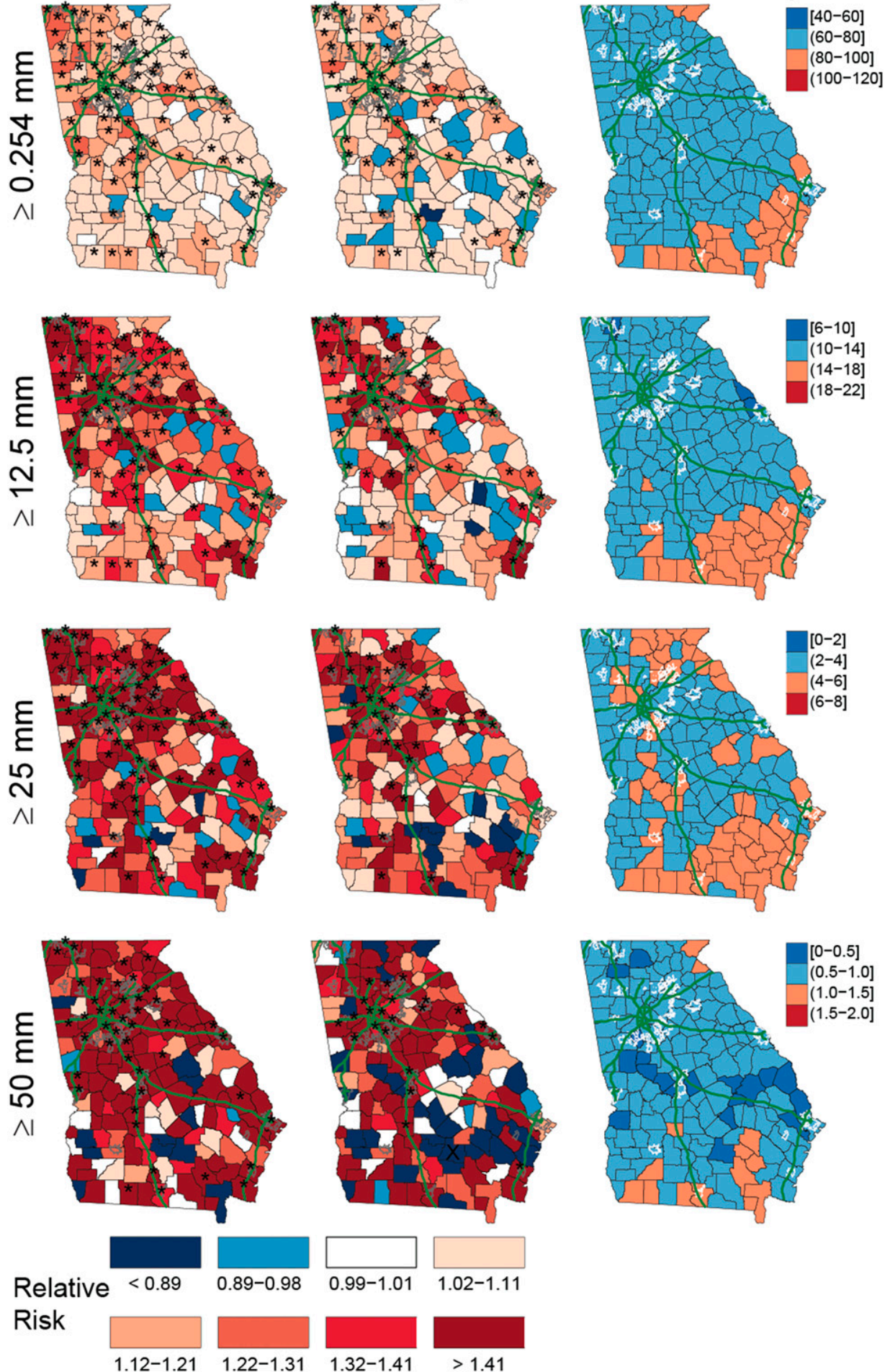

FIG. 5. As in Fig. 4, but for Georgia. 


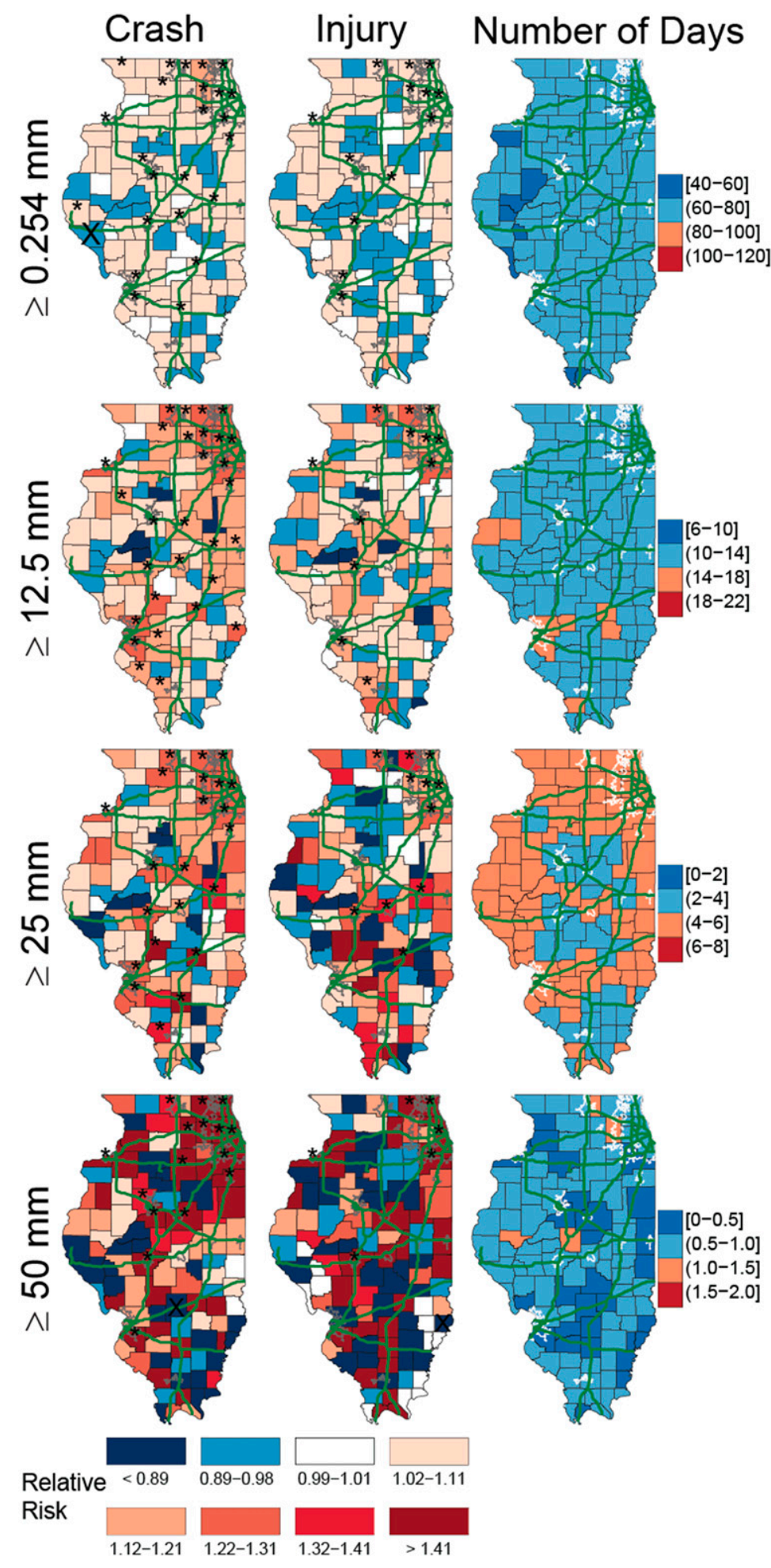

FIG. 6. As in Fig. 4, but for Illinois. 

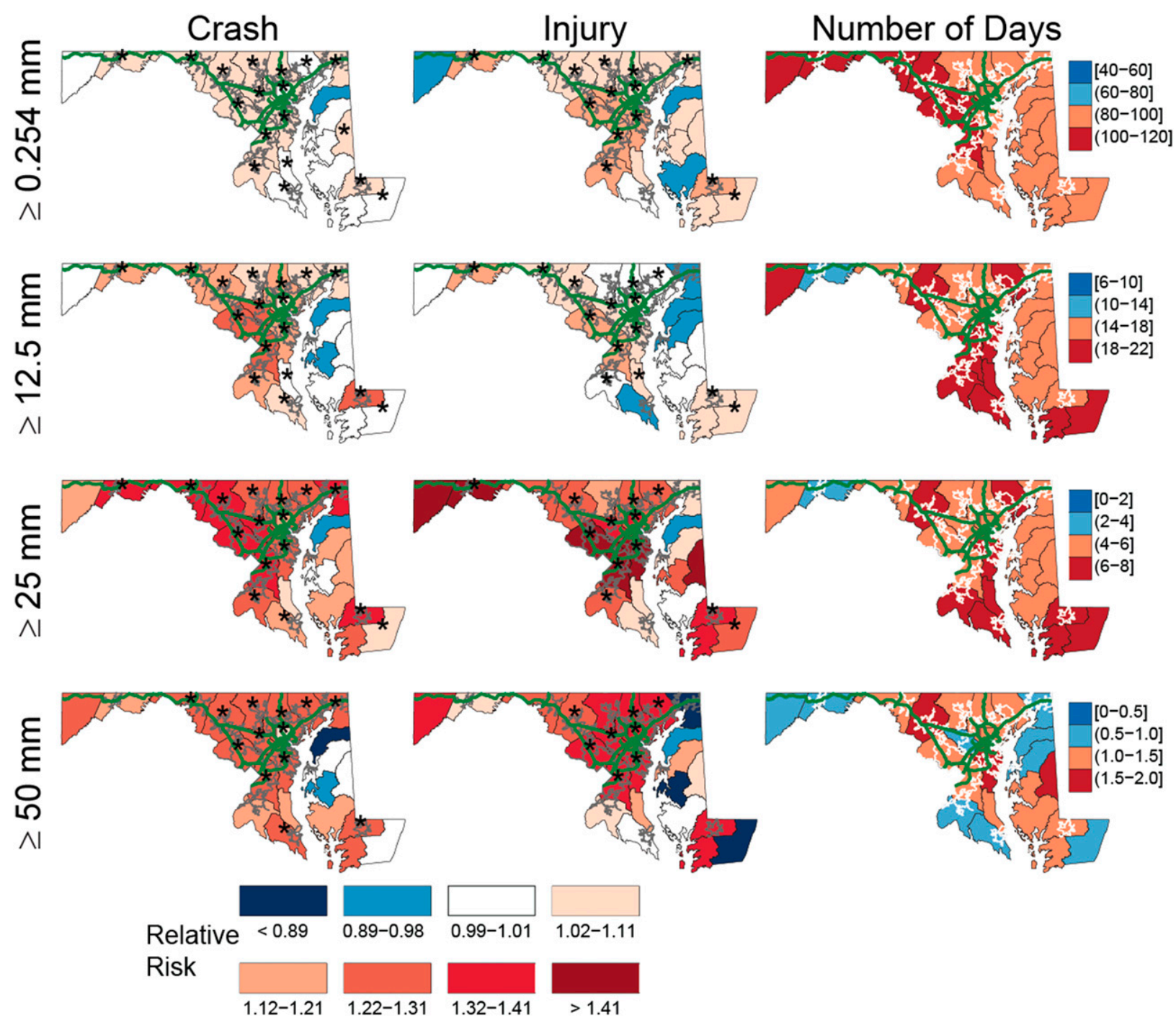

FIG. 7. As in Fig. 4, but for Maryland.

Many, but not all, rural interstate counties also follow this pattern but there is more variability in the risk estimates and fewer counties with significant increases in risk. In general, rural areas and areas without major highways see a much larger change in relative risk as compared to urban areas at each precipitation threshold. This is expected as rural counties with smaller population would experience relatively low collision counts under all circumstances (Fig. 1), which would be further reduced by only considering a small subset of the days that exceed the threshold in question. Spatially, these counties stand out as having very high or low estimates of relative risk that are not statistically significant at a given rainfall threshold, providing visual evidence of the wide confidence intervals that most likely result from low collision counts. However, significant increases in risk also appear in counties lacking major urban areas or major highways, and in some cases urban counties see decreases in relative risk, clearly illustrating that other factors must play a role in producing relative risk during rainfall.

\section{Conclusions}

Rainfall is one of a number of factors that can lead to an automobile crash. In this study, daily gridded rainfall and crash data were gathered for six states (Arkansas, Georgia, Illinois, Maryland, Minnesota, and Ohio) for the period 1996-2010, and a matched pair analysis was used to pair days with rainfall to dry days to determine the relative risk of crash, injury, and fatality. The main finding is that rainfall leads to a significant increase in 

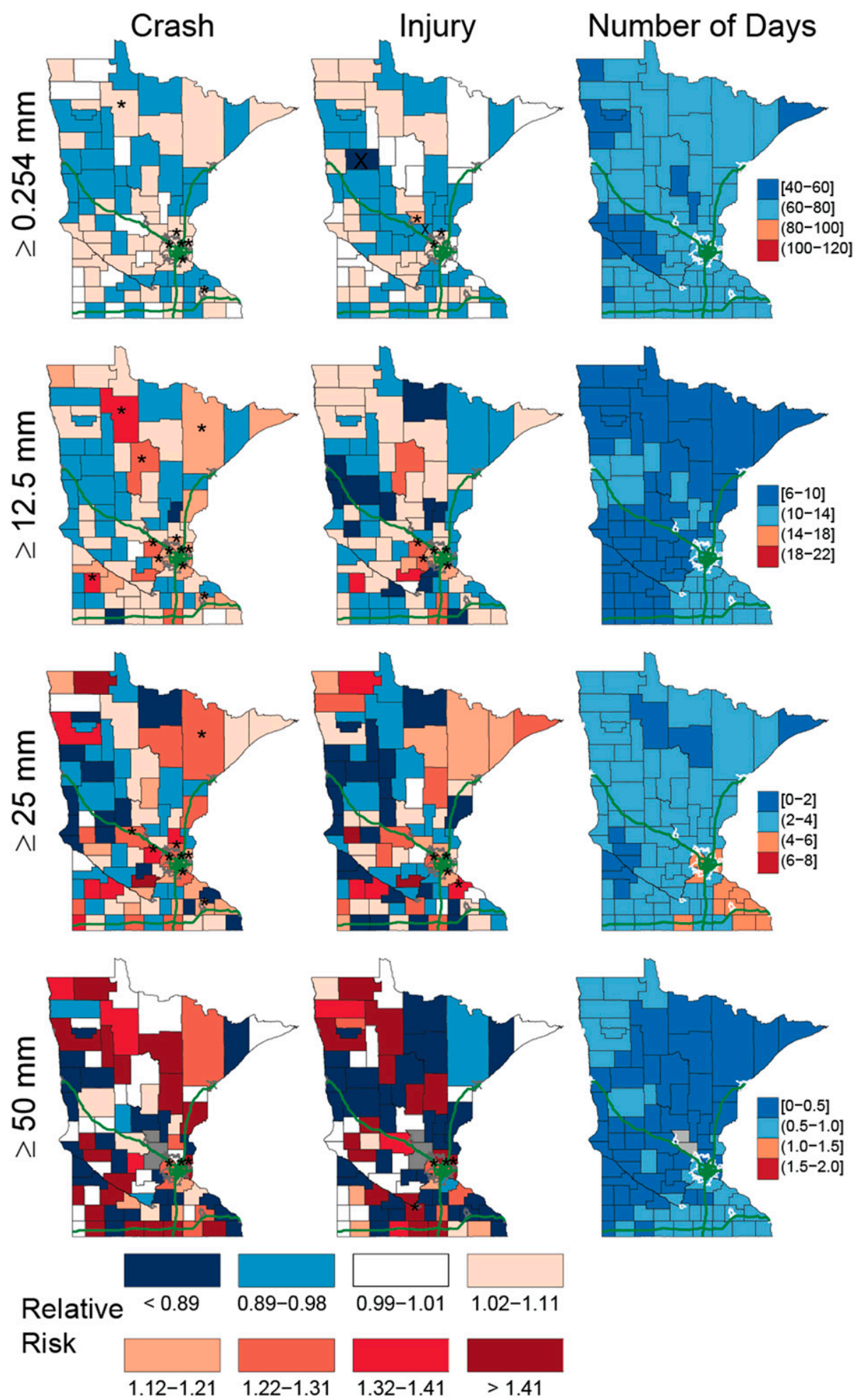

FIG. 8. As in Fig. 4, but for Minnesota. 

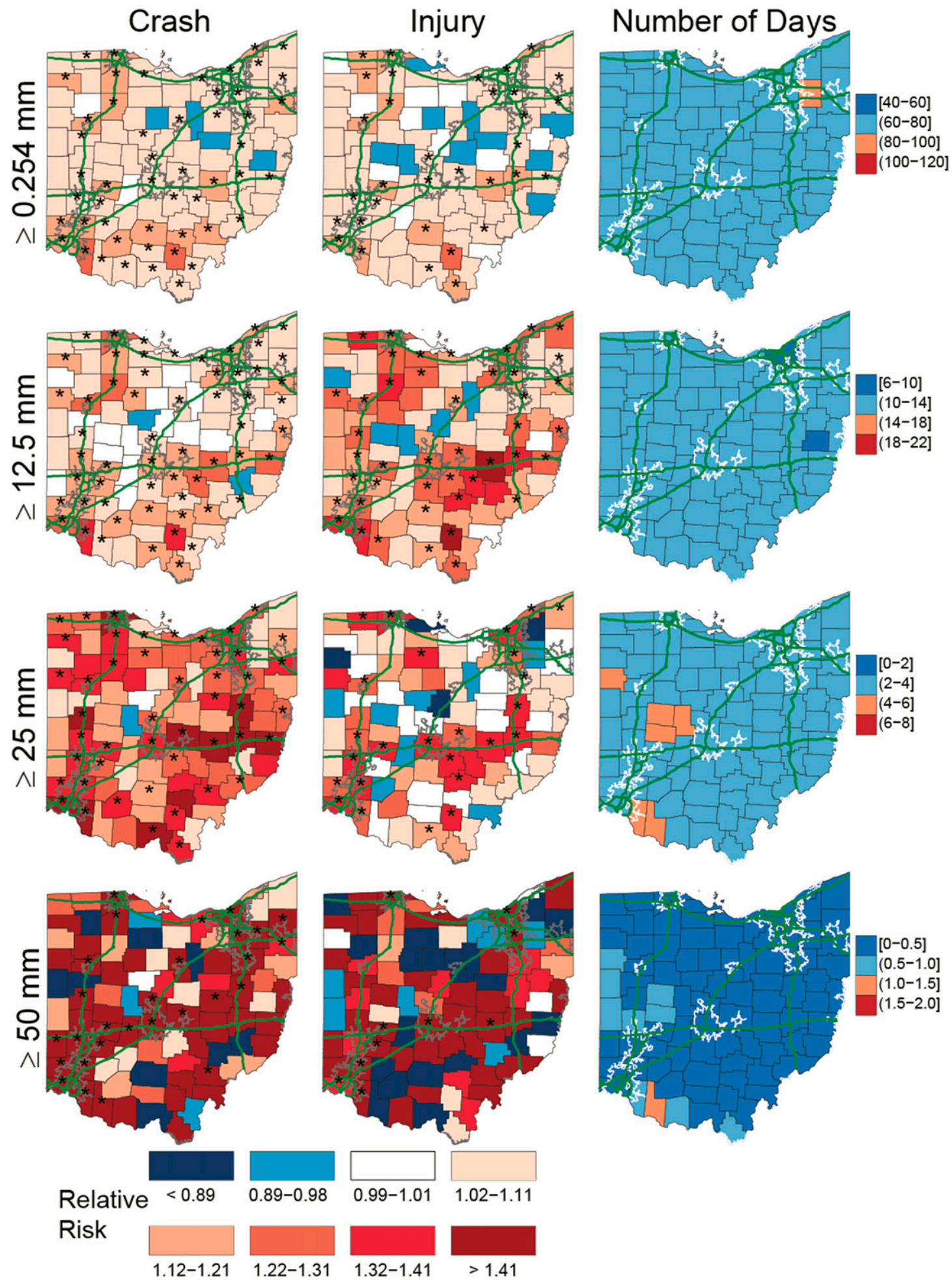

FIG. 9. As in Fig. 4, but for Ohio. 
the relative risk of $10 \%$ for crashes and $8 \%$ for injuries, with no significant change in the relative risk of fatality when compared to dry days.

Rainfall leads to over 28000 crashes, 12000 injuries, and $\$ 381$ million dollars in economic losses in the study states each year relative to what would be expected if no rain occurred. Relative risk was higher on days with greater precipitation accumulation, with crash risk increasing by $51 \%$ on days with at least $50 \mathrm{~mm}$ as compared to dry days. Overall, traffic volume reductions due to exposure in the six study states estimated from the results of Keay and Simmonds (2005) led to an approximately $1 \%$ increase in relative risk for all crashes, but with a much greater effect on days with at least $50 \mathrm{~mm}$ of rain.

The gridded precipitation data used in this study allow for a more complete examination of the spatial variation in relative risk than previous studies that used meteorological station data. Rural areas see the most extreme variations in relative risk, but most of the significant increases in relative risk occur in urbanized counties and those with major highways where large numbers of motorists are exposed to rainfall when it occurs. While urban, rural interstate, and rural counties all saw increased risk during rainfall, urban counties had the largest increase. For example, while rural counties have a $26 \%$ increase in crash risk on days with rainfall $\geq 50 \mathrm{~mm}$, the crash risk in urban counties is $55 \%$ higher on those days, more than double the risk in rural areas and a significant finding given the large number of motorists in urban counties. While few studies have examined rural areas in detail, results show that they also experience significant increases in risk during rainfall, although smaller than those found in urban counties.

This research finds that there are also some exceptions to the general patterns observed and described above. As with previous studies (Black and Mote 2015b; Andrey et al. 2003, 2013) the relative risk varies spatially in ways that are not explained solely by meteorological factors. The results of this research support the findings of Andrey et al. (2013), who conclude that drivers do not necessarily become acclimated to local rainfall patterns. There is no clear link between the number of rainfall days at a particular threshold in each county and relative risk. Some counties exhibit increased relative risk during rainfall even when those conditions are frequently experienced by motorists, while other counties do not. Counties that average fewer rainfall days per year at a particular threshold do not necessarily exhibit increased crash risk as might be expected given the relative inexperience that drivers in those counties would presumably have with those conditions. A number of factors such as short-term driver adaptations and roadway characteristics all play a part in the overall risk of crash faced by motorists during rainfall. However, as climate changes, both the frequency and intensity of rainfall events will likely change. The results of this work show that greater daily precipitation totals, suggestive of more intense precipitation, strongly influence risk while the effect of rainfall frequency is mixed. Understanding the effects of each on crash risk is critical to continued improvements in road safety. It is hoped that continued research on both meteorological factors and driver operations during rainfall will lead to a reduced number of crashes in the future.

Acknowledgments. Alan Black and Gabriele Villarini acknowledge financial support by IIHR-Hydroscience and Engineering and the Iowa Flood Center. Funding by the USACE Institute for Water Resources is also acknowledged (Gabriele Villarini).

\section{REFERENCES}

Abdel-Aty, M., A. Ekram, H. Huang, and K. Choi, 2011: A study on crashes related to visibility obstruction due to fog and smoke. Accid. Anal. Prev., 43, 1730-1737, doi:10.1016/ j.aap.2011.04.003.

Andreescu, M., and D. B. Frost, 1998: Weather and traffic accidents in Montreal, Canada. Climate Res., 9, 225-230, doi:10.3354/ cr009225.

Andrey, J., 2010: Long-term trends in weather-related crash risks. J. Transp. Geogr., 18, 247-258, doi:10.1016/j.jtrangeo.2009.05.002.

_ Accid. Anal. Prev., 25, 465-472, doi:10.1016/0001-4575(93)90076-9.

, B. Mills, M. Leahy, and J. Suggett, 2003: Weather as a chronic hazard for road transportation in Canadian cities. Nat. Hazards, 28, 319-343, doi:10.1023/A:1022934225431.

_ D. Hambly, B. Mills, and S. Afrin, 2013: Insights into driver adaptation to inclement weather in Canada. J. Transp. Geogr., 28, 192-203, doi:10.1016/j.jtrangeo.2012.08.014.

Ashley, W. S., S. Strader, D. C. Dziubla, and A. Haberlie, 2015: Driving blind: Weather-related vision hazards and fatal motor vehicle crashes. Bull. Amer. Meteor. Soc., 96, 755-778, doi:10.1175/BAMS-D-14-00026.1.

Bergel-Hayat, R., M. Debbarh, C. Antoniou, and G. Yannis, 2013: Explaining the road accident risk: Weather effects. Accid. Anal. Prev., 60, 456-465, doi:10.1016/j.aap.2013.03.006.

Bertness, J., 1980: Rain-related impacts on selected transportation activities and utility services in the Chicago area. J. Appl. Meteor., 19, 545-556, doi:10.1175/1520-0450(1980)019<0545: RRIOST > 2.0.CO;2.

Black, A. W., and T. L. Mote, 2015a: Characteristics of winterprecipitation-related transportation fatalities in the United States. Wea. Climate Soc., 7, 133-145, doi:10.1175/WCAS-D-14-00011.1.

$\longrightarrow$, and _ 2015b: Effects of winter precipitation on automobile collisions, injuries, and fatalities in the United States. J. Transp. Geogr., 48, 165-175, doi:10.1016/j.jtrangeo.2015.09.007.

Blincoe, L. J., T. R. Miller, E. Zaloshnja, and B. A. Lawrence, 2015: The economic and societal impact of motor vehicle crashes, 2010 (revised). National Highway Traffic Safety Administration Rep. DOT HS 812 013, 304 pp. [Available online at https:// crashstats.nhtsa.dot.gov/Api/Public/ViewPublication/812013.] 
Brijs, T., D. Karlis, and G. Wets, 2008: Studying the effect of weather conditions on daily crash counts using a discrete time-series model. Accid. Anal. Prev., 40, 1180-1190, doi:10.1016/j.aap.2008.01.001.

Brodsky, H., and A. S. Hakkert, 1988: Risk of a road accident in rainy weather. Accid. Anal. Prev., 20, 161-176, doi:10.1016/ 0001-4575(88)90001-2.

Cools, M., E. Moons, and G. Wets, 2010: Assessing the impact of weather on traffic intensity. Wea. Climate Soc., 2, 60-68, doi:10.1175/2009WCAS1014.1.

Eisenberg, D., 2004: The mixed effect of precipitation on traffic crashes. Accid. Anal. Prev., 36, 637-647, doi:10.1016/ S0001-4575(03)00085-X.

—_ and K. E. Warner, 2005: Effects of snowfalls on motor vehicle collisions, injuries, and fatalities. Amer. J. Public Health, 95, 120-125, doi:10.2105/AJPH.2004.048926.

Elvik, R., 2006: Laws of accident causation. Accid. Anal. Prev., 38, 742-747, doi:10.1016/j.aap.2006.01.005.

—, A. Høye, T. Vaa, and M. Sørensen, 2009: The Handbook of Road Safety Measures. 2nd ed. Emerald Group Publishing, $1124 \mathrm{pp}$.

Fleiss, J. L., B. Levin, and M. C. Paik, 2003: Statistical Methods for Rates and Proportions. 3rd ed. Wiley, $800 \mathrm{pp}$.

Fridstrøm, L., J. Ifver, S. Ingebrigtsen, R. Kulmala, and L. Krogsgård Thomsen, 1995: Measuring the contribution of randomness, exposure, weather, and daylight to the variation in road accident counts. Accid. Anal. Prev., 27, 1-20, doi:10.1016/ 0001-4575(94)E0023-E.

Hambly, D., J. Andrey, B. Mills, and C. Fletcher, 2013: Projected implications of climate change for road safety in Greater Vancouver, Canada. Climatic Change, 116, 613-629, doi:10.1007/ s10584-012-0499-0.

Higgins, R., W. Shi, E. Yarosh, and R. Joyce, 2000: Improved United States precipitation quality control system and analysis. NCEP/Climate Prediction Center ATLAS No. 7. Accessed 7 March 2016. [Available online at http://www.cpc.ncep.noaa.gov/ research_papers/ncep_cpc_atlas/7/index.html.]
Jaroszweski, D., and T. McNamara, 2014: The influence of rainfall on road accidents in urban areas: A weather radar approach. Travel Behav. Soc., 1, 15-21, doi:10.1016/j.tbs.2013.10.005.

Johansson, Ö., P. Wanvik, and R. Elvik, 2009: A new method for assessing the risk of accident associated with darkness. Accid. Anal. Prev., 41, 809-815, doi:10.1016/j.aap.2009.04.003.

Keay, K., and I. Simmonds, 2005: The association of rainfall and other weather variables with road traffic volume in Melbourne, Australia. Accid. Anal. Prev., 37, 109-124, doi:10.1016/ j.aap.2004.07.005

Levine, N., K. E. Kim, and L. H. Nitz, 1995: Daily fluctuations in Honolulu motor vehicle accidents. Accid. Anal. Prev., 27, 785796, doi:10.1016/0001-4575(95)00038-0.

Mills, B. N., J. Andrey, and D. Hambly, 2011: Analysis of precipitation-related motor vehicle collision and injury risk using insurance and police record information for Winnipeg, Canada. J. Safety Res., 42, 383-390, doi:10.1016/j.jsr.2011.08.004.

Olson, D. A., N. W. Junker, and B. Korty, 1995: Evaluation of 33 years of quantitative precipitation forecasting at the NMC. Wea Forecasting, 10, 498-511, doi:10.1175/1520-0434(1995)010<0498: EOYOQP $>2.0 . \mathrm{CO} ; 2$.

Qiu, L., and W. A. Nixon, 2008: Effects of adverse weather on traffic crashes. Transp. Res. Rec., 2055, 139-146, doi:10.3141/2055-16.

Sherretz, L. A., and B. C. Farhar, 1978: An analysis of the relationship between rainfall and the occurrence of traffic accidents. J. Appl. Meteor., 17, 711-715, doi:10.1175/1520-0450(1978)017<0711: AAOTRB $>2.0 . \mathrm{CO} ; 2$.

Theofilatos, A., and G. Yannis, 2014: A review of the effects of traffic and weather characteristics on road safety. Accid. Anal. Prev., 72, 244-256, doi:10.1016/j.aap.2014.06.017.

U.S. Census Bureau, 2015: 2010 urban and rural classification. Accessed 7 March 2016. [Available online at https://www. census.gov/geo/reference/ua/urban-rural-2010.html.]

Xie, P., A. Yatagai, M. Chen, T. Hayasaka, Y. Fukushima, C. Liu, and S. Yang, 2007: A gauge-based analysis of daily precipitation over East Asia. J. Hydrometeor., 8, 607-626, doi:10.1175/JHM583.1. 